$\begin{array}{ll} & \text { Etnográfica } \\ \text { etnográfica } & \text { Revista do Centro em Rede de Investigação em }\end{array}$

Antropologia

vol. 21 (3) | 2017

Vol. 21 (3)

\title{
A (des)habitação enquanto um disciplinamento moral e uma prática de Estado na criação de territórios
}

Housing and dislocation as State practice and moral discipline in creating territories

\section{Anelise dos Santos Gutterres}

\section{(Q) OpenEdition}

\section{Journals}

\section{Edição electrónica}

URL: https://journals.openedition.org/etnografica/5049

DOI: 10.4000/etnografica.5049

ISSN: 2182-2891

\section{Editora}

Centro em Rede de Investigação em Antropologia

\section{Edição impressa}

Data de publição: 1 outubro 2017

Paginação: 569-583

ISSN: 0873-6561

\section{Refêrencia eletrónica}

Anelise dos Santos Gutterres, «A (des)habitação enquanto um disciplinamento moral e uma prática de Estado na criação de territórios», Etnográfica [Online], vol. 21 (3) | 2017, posto online no dia 24 março 2018, consultado o 11 fevereiro 2022. URL: http://journals.openedition.org/etnografica/5049 ; DOI: https://doi.org/10.4000/etnografica.5049

\section{(c) (7) \&}

Etnográfica is licensed under a Creative Commons Attribution-NonCommercial 4.0 International License. 


\section{A (des)habitação enquanto um disciplinamento moral e uma prática de Estado na criação de territórios}

\section{Anelise dos Santos Gutterres}

Inserida na área da antropologia urbana e de uma antropologia do Estado, a pesquisa tem como ponto de partida os processos de reconfiguração e transformação urbana na cidade do Rio de Janeiro nos últimos anos, apontando para um aumento, provocado pelo município, dos deslocamentos forçados das famílias que habitam áreas periféricas e de favelas. Compreendendo esse movimento de (des)habitação como uma prática da governamentalidade na construção de territórios de vulnerabilidade, trazemos algumas reflexões sobre as ações do Estado nestes locais, a partir de um percurso etnográfico pelos processos judiciais de um núcleo especializado da Defensoria Pública do Estado do Rio de Janeiro, o Núcleo de Terras e Habitação, e de um retorno a uma pesquisa anterior na região portuária do Rio de Janeiro.

PALAVRAS-CHAVE: favelas, habitação, Estado, Defensoria Pública, Rio de Janeiro, urbano.

Housing and dislocation as State practice and moral discipline in creating territories - This research is inscribed in urban anthropology and State anthropology and assumes as its starting point the processes of urban transformation and reconfiguration in the city of Rio de Janeiro in recent years, revealing an increase of forced displacements imposed by the city government upon families residing in peripheral and poor areas (favelas). This (un)housing movement is seen as a governmentality practice associated with the construction of vulnerability territories. State actions in those areas are examined through an ethnographic approach of legal causes involving a specialized unit of the public defence office of the State of Rio de Janeiro which is devoted to land and housing issues, and also drawing on previous research in the port area of the city.

KEYWORDS: slums, housing, State, public defence, Rio de Janeiro, urban.

GUTTERRES, Anelise dos Santos (adsgutterres@gmail.com) - Programa de pós-graduação em Antropologia Social, Museu Nacional/UFRJ, Brasil. 


\section{INTRODUÇÃO}

Esse artigo é resultado de percursos sobrepostos. ${ }^{1}$ Explora o desdobramento de algumas hipóteses elaboradas em meu projeto de pós-doutorado, cujas falhas e surpresas vivenciadas serão descritas neste texto a partir de um trabalho de campo realizado na sede de um núcleo especializado da Defensoria Pública do Estado do Rio de Janeiro, durante aproximadamente seis meses do ano de 2016, e representa também um retorno aos dados de minha pesquisa de doutorado, às entrevistas, reportagens e documentos reunidos durante a etnografia que realizei com moradoras e moradores ameaçados de remoção na zona portuária do Rio de Janeiro, entre agosto de 2011 e dezembro de $2013 .{ }^{2}$

Entre as diversas razões que motivam os percursos acima descritos está o término dos Jogos Olímpicos no Rio de Janeiro em agosto de 2016, que configura o que foi chamado - por jornalistas e também por colegas que atuam em movimentos sociais, organizações não governamentais ou, como eu, produzindo pesquisas através da universidade - de "o fim da era dos megaeventos" ${ }^{3}$ na capital fluminense. A expressão se refere ao término do período, de aproximadamente 15 anos, que se inicia com a escolha e divulgação do Rio de Janeiro como sede de grandes eventos esportivos. Uma "era" que incluiria os Jogos Pan-Americanos, anunciados em 2002 e realizados em 2007 no Rio de Janeiro; a Copa do Mundo, cuja escolha do país sede fora divulgada em 2007, para realização em 2014, no Rio de Janeiro e em mais 11 cidades brasileiras; finalmente os Jogos Olímpicos e Paralímpicos, que foram anunciados em um grande evento na praia de Copacabana, ${ }^{4} \mathrm{em} 2009$, e realizados entre agosto e setembro de 2016, também na cidade do Rio de Janeiro.

A observância de uma "era dos megaeventos" me impulsionou à construção de um projeto de pesquisa junto aos arquivos e documentos do Núcleo de

I Tal como sugerido na chamada especial para o número comemorativo, este artigo explora os argumentos de meu projeto de pesquisa de pós-doutorado, recebendo o mesmo nome desta investigação ainda incipiente na época em que submeti o material à publicação, em maio de 2016. Gostaria de agradecer as sugestões contidas no parecer recebido da revista Etnográfica e esclarecer que o texto é uma versão reduzida de outro artigo que traz novas abordagens reflexivas aos dados aqui contidos.

2 O projeto de pós-doutorado está vinculado ao PPGAS/MN-UFRJ pelo período de 2016-2021, e para esse projeto recebo uma bolsa Capes através do PNPD. A pesquisa de doutorado resultou na tese que defendi em dezembro de 2014 no PPGAS/UFRGS, e para a sua realização recebi uma bolsa de estudos, de março de 2010 a março de 2014, do Programa de Apoio a Planos de Reestruturação e Expansão das Universidades Federais (Reuni) da Capes.

3 Ver "Brasil se despede da Olimpíada e encerra era dos megaeventos", Jornal do Brasil, 22 de agosto de 2016, disponível em < www.jb.com.br/olimpiada-2016/noticias/2016/08/22/brasil-se-despede-daolimpiada-e-encerra-era-dos-megaeventos/ > (última consulta em outubro de 2017).

4 Há diversas reportagens que descrevem e noticiam este evento; no entanto, destaco o trabalho de Damo e Oliven (2013), que o relata de forma crítica destacando os alinhamentos políticos que propiciaram o acolhimento dos jogos no país. 
Terras e Habitação (NUTH $)^{5}$ da Defensoria Pública do Estado do Rio de Janeiro (DPGERJ), coletivo que foi ativo na defesa de grupos de familiares e moradores dos territórios em ameaça de remoção, sustentando ações civis públicas (ACP) contra a municipalidade e que visavam reverter o quadro das remoções durante o período de preparação para os eventos no município. Sobre a pesquisa com documentos é importante destacar o trabalho de Mariza Peirano (1986), que, em diálogo com Wanderley Guilherme dos Santos, reflete sobre a relevância de determinados documentos na construção da cidadania, acesso aos direitos civis, políticos e sociais no Brasil. Na discussão trazida pela autora, eles seriam símbolos de identidade cívica, fornecidos por órgãos públicos, e sua obtenção exigiria "determinados requisitos estipulados por lei", o que marcaria principalmente as camadas pobres, já que seria utilizado como quesito de diferenciação e distinção entre o "cidadão" e o "marginal". No caso de nossa pesquisa, vimos que a posse de determinados documentos era constantemente assinalada por defensores e defensoras como elemento imprescindível para a montagem das ações, já que tinham a função de comprovação formal da existência do objeto e da veracidade das razões do processo. Entre os documentos principais do processo que asseguravam a atuação da Defensoria Pública estava o atestado de hipossuficiência, geralmente realizado por autodeclaração, preenchida e assinada pelo "assistido". ${ }^{6}$ Inicialmente também eram anexados ao processo algum comprovante de residência - e para tal era aceita uma gama muito variada de documentos - e uma cópia da carteira de identidade. A entrega desse conjunto de documentos habilitava o morador ameaçado de remoção à categoria de "assistido". A partir desse momento, o simbolismo dos documentos, tal qual nos fala Peirano, ganhava uma importância cotidiana, já que essas famílias e/ou sujeitos assistidos começavam também a vivenciar uma lógica de recolhimento e guarda de determinados documentos que julgavam serem potenciais provas da veracidade de suas declarações, materializando a violência à qual estavam expostos. ${ }^{7}$ Tal como preconiza Veena Das (2007: 240), nossas vidas

5 Núcleo especializado que atua na assistência a casos de conflitos em loteamentos, conjuntos, casas e terrenos em áreas urbanas, e cujos "assistidos" enquadravam-se nos parâmetros da hipossuficiência.

6 Ou seja, uma comprovação de que o declarante tem uma situação econômica que não lhe permite pagar os custos do processo e os honorários advocatícios sem prejuízo do sustento próprio ou da família. É importante notar que não é imprescindível que seja configurado o estado de miserabilidade do "assistido" (como são chamados pelas defensoras e defensores aqueles que impetram a ação) para que se enquadre nessa classificação.

7 Como viemos observando, são as mulheres que com mais frequência se ocupam do recolhimento e guarda de tais documentos. Nos períodos em que acompanhei o trabalho do Núcleo, presenciei diversas vezes os relatos de que elas tinham saído mais cedo do trabalho para comparecer na Defensoria, cujo horário de atendimento regular era até às $15 \mathrm{~h}$. Eram elas que avaliavam os papéis que poderiam constar como prova, que pressionavam por respostas (ligando ou comparecendo na sede), que os levavam até o Núcleo para que fossem copiados, na esperança de que pudessem contribuir para o andamento do processo e um desfecho favorável a elas. 
em geral são permeadas por documentos. A forma da nossa existência, onde podemos ou não podemos circular, é demarcada por papéis que encadeiam certos processos. Após, ou mesmo no momento de produção do "termo de declaração", era recorrente, portanto, que os assistidos e as assistidas passassem a oferecer aos defensores e defensoras uma quantidade de papéis, certos de que sua quantidade auxiliaria na comprovação da ação nebulosa dos agentes do município, tal como relatado nos sucessivos atendimentos. Esse termo, como veremos, é um documento que também é assinado pelo assistido ou assistida e é o espaço onde ele/ela relata de maneira descritiva a opacidade das ações do município na localidade. Notamos que, para os assistidos e assistidas, esses documentos buscam comprovar a palavra falada e inscrita nos termos de declaração. E também é um processo de resgate e manutenção da dignidade, uma tentativa de tornar visível um emaranhado de atores e práticas produzidas para serem ilegíveis. Tratando esse conjunto híbrido de documentos que compõem os processos judiciais como "artefatos paradigmáticos das práticas do conhecimento moderno” (Riles 2006; Ferreira 2013, 2015), nosso objetivo é, por um lado, refletir sobre seu simbolismo enquanto percurso de produção de uma luta por reconhecimento que passa pela manutenção da dignidade, e, por outro lado, compreender melhor as "assinaturas" produzidas pelo Estado na gestão da habitação em áreas de favelas e periferias na "era dos megaeventos". ${ }^{8}$ Estaremos, portanto, olhando para os documentos produzidos para concepção e sucesso do processo, mas também para os relatos, sejam indiretos - através dos documentos, de meu percurso por eles e também através das declarações e anotações escritas -, sejam escutados diretamente em campo.

A hipótese que me incitou a olhar com mais vagar para o lado de lá do balcão, ${ }^{9}$ ou seja, mergulhar nos documentos produzidos pelos processos, foi a

8 Aproveito para fazer referência a etnografias fundamentais realizadas em instituições estatais ou entre e a partir de documentos e processos, e que foram (e são) fundamentais na construção das reflexões e descrições aqui apresentadas. Destaco, portanto, o trabalho de Lugones (2009) sobre os tribunais de menores em Córdoba; o de Schuch (2009) junto à Fundação de Atendimento Socioeducativo em Porto Alegre; os de Claudia Fonseca $(1997,2004)$, que analisou documentos dos processos de disputa pela guarda de crianças no início do século XX e também analisou os processos de investigação da paternidade em diferentes instâncias jurídicas de Porto Alegre; a pesquisa de Adriana Vianna (1999) junto aos registros policiais que classificam determinada população infanto-juvenil no início do século XX; e o trabalho de Antonio Carlos de Souza Lima (1995) sobre o poder tutelar como exercício de poder de determinados aparelhos de governo.

9 Uso a expressão "do lado de lá" porque não sou funcionária ou integrante do corpo de operadores da Justiça. Como participei ativamente do apoio aos moradores e moradoras da Providência, frequentando os atendimentos na Defensoria ao lado deles e delas, me colocava até o princípio desta pesquisa, apesar de não ser assistida, no lugar de quem está "do lado de cá" do balcão. Quando passei a realizar a investigação dentro do Núcleo, essa condição foi aos poucos se transformando, e frequentemente eu era confundida com as "doutoras" - no contexto, mulheres brancas com formação universitária. Essa situação me levou a buscar espaços para refletir sobre a branquitude do judiciário (e da academia), tema de extrema relevância, mas que, no entanto, não abordarei neste artigo. 
evidência empírica de que este ínterim - 2007 a 2016 - foi caracterizado por uma dinâmica de tensão e conflito na propalação de programas de urbanização e/ou produção de moradias de interesse social por agentes do município do Rio de Janeiro, especialmente na implementação do Programa Morar Carioca, do Programa de Aceleração de Crescimento (PAC) e do Programa Minha Casa, Minha Vida (PMCMV) em localidades próximas às áreas utilizadas para a realização dos megaeventos, ou em favelas "pacificadas" escolhidas para receberem obras vultuosas (em cifras e tamanho), geralmente associadas nos discursos políticos à retomada da cidadania (e dignidade) nesses locais. Na análise das motivações dessas ações civis públicas, mesmo guiada pela hipótese de que havia recorrências que uniam essas ações, busquei olhar também para as particularidades de cada processo, com especial atenção para como a comunicação entre os defensores e defensoras do NUTH neste período - envolvendo secretarias, departamentos, institutos, peritos, relatórios, apoiadores, técnicos, especialistas, plantas, croquis, projetos, reportagens jornalísticas - foi produzindo uma rede de instituições, grupos e documentos que acabaram desenhando a gestão do Estado nos territórios durante esse período e também como ela foi se moldando nesta época para efetividade dessa gestão.

Do lado de cá do balcão, eu estava baseada na pesquisa realizada para o meu doutorado, onde acompanhei a formação de algumas redes de contestação às obras dos "megaeventos" no Brasil e as recorrências da governamentalidade na gestão da habitação dos pobres em diferentes localidades do país durante o período de preparação para tais eventos. ${ }^{10}$ Diferentes documentos produzidos durante esse período - 2009 a 2012 - mostravam recorrências nas ilegalidades realizadas pela prefeitura do Rio de Janeiro em diferentes regiões da cidade, fossem trabalhos acadêmicos (Faulhaber 2012; Fernandes 2013; Magalhães 2013), ou documentação produzida por coletivos civis organizados, ${ }^{11}$ ou trabalhos de jornalistas correspondentes de veículos de mídia internacional e nacional.

Analisando a data dos primeiros atendimentos, de 2002 a 2014, e os termos de declaração recebidos pelo NUTH neste período, fomos construindo um mapeamento do que estamos chamando de "assinaturas" do Estado na gestão da moradia em territórios de favela e periferias do Rio de Janeiro nesta

10 Como já ressaltado na tese (Gutterres 2014), essa forma de atuação - e por essa razão utilizo a noção de governamentalidade (Foucault 2008) - foi observada em periferias, centros de cidade e favelas das cidades-sede durante todo o período de preparação para a realização da Copa do Mundo FIFA no país.

11 Ver, por exemplo, o dossiê Megaeventos e Violaçães de Direitos Humanos no Brasil, lançado em 2011 pela Articulação Nacional dos Comitês Populares da Copa (disponível em https://apublica.org/wp-content/ uploads/2012/01/DossieViolacoesCopa.pdf), ou as versões regionais produzidas pelo Comitê Popular da Copa e Olimpíadas do Rio de Janeiro com o título Megaeventos e Violação dos Direitos Humanos no Rio de Janeiro, cuja primeira edição foi lançada em 2012 (disponível em < https://comitepopulario.files. wordpress.com/2012/04/dossic3aa-megaeventos-e-violac3a7c3b5es-dos-direitos-humanos-no-rio-dejaneiro.pdf $>$ ). 
última década. A montagem deste panorama tem como objetivo averiguar a abrangência das práticas de remoção enquanto um esforço de (des)habitação dessa população e, consequentemente, na produção de territórios de vulnerabilidade. Tal como sugerido no trabalho de Machado da Silva e Figueiredo (2015) nos anos 80 - onde ressaltam que a reivindicação da urbanização nas favelas cariocas não suprimia as remoções e, ao contrário, poderia ser utilizada para justificá-las -, vimos os programas de urbanização propostos nesse período com cautela. Nossa pesquisa mostrou a relevância da previsão dos autores, já que muitos dos programas de urbanização propalados na época utilizaram a necessidade e o desejo de urbanização por parte dos moradores - leia-se saneamento básico, iluminação, arruamento, acessibilidade - para efetivação da remoção parcial ou total das moradias em diferentes localidades. ${ }^{12}$ Por essa razão, é necessário dizer que entendemos a "urbanização" como uma categoria em disputa, ao passo que "remoção" seria uma categoria de luta - geralmente empregada pelos movimentos sociais ou moradores ligados a eles para dar visibilidade a ações de esbulho e turbação de posse, promovidas pela prefeitura municipal em moradias de diferentes favelas da cidade no ínterim destes eventos. A fim de visualizar parte do universo em que a disputa se dá, faremos um pequeno panorama dos programas (1) Minha Casa, Minha Vida, (2) Morar Carioca e (3) Programa de Aceleração do Crescimento, com o objetivo de contextualizar sua implementação no período de interesse desta pesquisa. Conforme as descrições feitas por Rachel Barros Oliveira (2016) em sua pesquisa sobre a política do PAC e da UPP na área de Manguinhos, no Rio de Janeiro, nota-se que as regiões que receberam tais programas foram elegidas cuidadosamente em uma rede de articulações conjunturais que envolvem interesses e afetos em diferentes níveis de arranjos locais, político-partidários, empresariais. ${ }^{13}$ A formação dessa rede é um efeito e uma condição da execução dessas políticas que também observamos em situações similares nas áreas onde o Morar Carioca e o PMCMV foram implementados.

Lançado em 2009, o Programa Minha Casa, Minha Vida subsidia a aquisição "da casa própria" para pessoas com diferentes rendas. Salvo exceções, estaremos nos referindo nesse artigo aos subsídios (até 96\%) àquelas famílias que têm rendimento entre zero e R\$1600. Destacada por Silva (2016: 238)

12 Conforme destacam Damo e Oliven (2013: 34-37) o Brasil possuía em 2009 o 8. ${ }^{\circ}$ PIB mais alto do mundo, a taxa de desemprego era baixa e houve um aumento de $54 \%$ no número de trabalhadores com ocupação formal na última década. Também ressaltam os avanços nas áreas sociais, com a implementação e ampliação da política de cotas raciais e étnicas nas universidades públicas e a instituição da bolsa-família.

13 Rachel Barros Oliveira (2016) mostra como diferentes arranjos foram feitos durante a realização da obra na região, envolvendo distintos níveis de poder local, lideranças comunitárias, criação de instâncias de participação, agentes da prefeitura e de outras instituições, além de uma ampla ressignificação dos sentidos da "chegada da obra" pelos moradores desse complexo de favelas. 
como a "faixa de interesse social", essa faixa 1 difere das outras duas faixas de rendimento, que são consideradas "de mercado" e onde o percentual do financiamento é menor. ${ }^{14} \mathrm{Em}$ uma nota publicada em novembro de 2014, uma rede de pesquisadores argumenta que a existência de conflito na propalação do programa durante a "era dos megaeventos" foi recorrente, apontando que a promoção do PMCMV "vem sendo utilizada para viabilizar remoções forçadas, muitas vezes não justificadas por necessidades habitacionais". ${ }^{15}$

No contexto do município do Rio de Janeiro, o programa Morar Carioca foi lançado em 2010 com o objetivo de "urbanizar, até 2020, todas as comunidades da cidade, integrando efetivamente ao tecido urbano do Rio essas áreas historicamente menos assistidas". Apesar de seu nome remeter para a moradia, suas maiores ações são no âmbito da "urbanização", com pavimentação, construção de redes e ligação de água, ligações de esgoto, muros de contenção de encostas, construção de espaços de desenvolvimento infantil (EDI), creches, instalação de iluminação pública, construção de escolas, praças, reservatórios de água e também de habitações. Na favela da Providência, localizada na região portuária do Rio de Janeiro, onde desenvolvi parte da pesquisa que resultou em meu doutorado, a implementação do Morar Carioca foi deveras violenta para um grupo de moradores, inclusive culminando em um pedido de assistência judicial junto ao NUTH.

Conforme refere o documento que traz o balanço dos primeiros quatros anos da implementação do PAC no Rio de Janeiro, o programa foi uma resposta aos primeiros desafios vencidos pelo presidente Lula da Silva em seu primeiro mandato (2003-2007), que teria estabilizado a economia nacional e implementado um novo modelo de desenvolvimento que combinava crescimento

14 Repito a revisão feita por Silva (2016), ressaltando os recursos que viabilizam a manutenção e incremento do PMCMV: Fundo de Garantia por Tempo de Serviço (FGTS), Sistema Brasileiro de Poupança e Empréstimo (SBPE), Fundo de Arrendamento Residencial (FAR), Orçamento Geral da União (OGU) e FNHIS (Fundo Nacional de Habitação de Interesse Social). Em seu trabalho, a autora acompanha a complexidade que envolve o programa, do ponto de vista de uma de suas beneficiárias, além das diferentes transformações que ele acarreta no local onde é construído.

15 Com o objetivo de avaliar o PMCMV, o Conselho Nacional de Desenvolvimento Científico e Tecnológico (CNPq) e o Ministério das Cidades lançaram em 2012 um edital de pesquisa. Onze das equipes contempladas formaram a Rede Cidade e Moradia e avaliaram empreendimentos em 22 municípios de seis estados: Pará, Ceará, Rio Grande do Norte, Minas Gerais, Rio de Janeiro e São Paulo. Partindo de um objetivo comum de análise sobre os processos de inserção urbana dos conjuntos construídos para a chamada "faixa l", as equipes abordaram temáticas e localidades específicas: dos projetos arquitetônicos e urbanísticos aos canteiros de obra e desempenho ambiental das unidades entregues; dos agentes operadores do programa, que passam pelos poderes locais, Caixa Econômica Federal e movimentos sociais, ao trabalho social realizado em empreendimentos selecionados. Os relatórios de pesquisa apontam para problemáticas estruturais do programa que têm impactado as cidades e a vida das famílias beneficiárias. Ver nota pública da Rede Cidade e Moradia disponível em <https://raquel rolnik.wordpress.com/2014/1 1/10/programa-minha-casa-minha-vida-precisa-ser-avaliado-nota-publicada-rede-cidade-e-moradia/ > (última consulta em outubro de 2017). 
com distribuição de renda. Publicada em 2010, a avaliação do Comitê Gestor do Programa indicava que "a economia brasileira reunia indicadores positivos como poucas vezes na história" e, "com a casa arrumada e um cenário internacional extremamente favorável”, a implementação do PAC abria um "horizonte de possibilidades". As palavras usadas pelos redatores do relatório demonstram a tônica destes anos: de um grande entusiasmo que culminava na chegada do "momento de avançar". ${ }^{16}$ Do ano de 2010 em diante, as cifras do programa aumentaram proporcionalmente no volume e na variedade dos empreendimentos. O PAC teve, portanto, diversas modalidades - PAC Mobilidade, Favelas, Centros Históricos -, construindo obras muito diferentes: creches, ciclovias, quadras esportivas, unidades básicas de saúde (UBS), equipamentos para esporte de alto desempenho, além da urbanização e construção de unidades habitacionais.

Feito esse pequeno resumo sobre os programas de urbanização e habitação com os quais estamos dialogando no corpo desse artigo, e também de alguns enredos que nutrem nossa pesquisa, buscarei descrever meu percurso pelo material pesquisado, em um conjunto híbrido de narrativas e momentos. Nossa intenção não é reconstruir linearmente os passos do processo e, portanto, estamos trabalhando com algumas partes deles, enfatizando as marcas da presença e daquilo que estamos chamando de esforço de (des)habitação dessa população de seus territórios de moradia.

\section{REUNIÕES E ALTERNATIVAS}

Uma das primeiras pastas que analisei continha documentos referentes à localidade conhecida como Estradão, localizada na zona oeste da cidade. As pastas eram quase sempre azuis, na capa continham o nome da comunidade, e na lombada havia uma numeração de referência.

Contendo três páginas, o "termo de primeiro atendimento" da pasta relativa ao setor dois, ${ }^{17}$ foi realizado no ano de 2013 por uma servidora pública "responsável pelo atendimento", cujo nome aparece no final do documento acima de seu número de matrícula. Nele, três pessoas, duas mulheres e um homem, são consideradas "declarantes", e seus nomes constam no topo da página, seguidos de indicação de nacionalidade, estado civil, ocupação, inscrição no CPF, residência e domicílio, telefone. As duas mulheres que comparecem para esse atendimento se declaram "do lar", e o homem declara-se aposentado

16 Conforme nosso levantamento, entre 2000 e 2002 foram iniciados 17 processos que tiveram como réu o município/prefeitura do Rio de Janeiro; entre 2003 e 2009 foram iniciados 53 processos; já entre 2010 e 2016 foram iniciados 84 processos. Há pelo menos seis localidades que têm mais de um processo tramitando em seu território.

17 As pastas da comunidade do Estradão estavam divididas por suas intervenções (setores), já que produziram processos diferentes. 
de um equipamento de saúde que funcionava dentro da comunidade havia muitos anos.

$\mathrm{Na}$ "ação cautelar exibitória" que consta no processo eletrônico desta comunidade, a secção nominada "Dos fatos" também se embasa em relatos da experiência dos moradores, expressa nas declarações de atendimentos. Assinada por defensores do NUTH em dezembro de 2013, a ação promove uma narrativa do processo que busca evidenciar a opacidade das investidas do réu na comunidade. ${ }^{18}$ No início desta secção, portanto, temos a afirmação de que "os moradores do Estradão viviam ali há mais de 20 anos". Abaixo, sabemos que, em 25 de julho de 2008, uma lei municipal declarou a área da comunidade como "Área de especial interesse social". Reforça-se que "há cerca de 1 ano, os moradores dos setores 2 e 3 vêm recebendo a visita de agentes da Secretaria de Habitação e da Subprefeitura da Barra da Tijuca". Na "visita", os moradores e moradoras ficam sabendo que "a área será alvo do referido Projeto Morar Carioca e que serão necessárias remoções de residências". Mesmo com as visitas já iniciadas em 2012, um decreto de janeiro de 2013 "ratifica e regulamenta a área como sendo de especial interesse social, inclusive com a previsão de regularização fundiária". Os defensores citam o envio de diversos ofícios a fim de obter informação da prefeitura. Por outro lado, os moradores e moradoras também pressionaram por informações junto à secretaria e subprefeitura, constando na ação que eles teriam conseguido uma reunião no interior da subprefeitura em julho de 2013. Apresentando um folder que indica, "em linhas superficiais", as intervenções na área, os agentes não apresentaram nessa reunião "de forma clara e precisa" quais seriam os tipos e locais de intervenção no interior daquelas áreas, "número de famílias atingidas e formas a serem oferecidas para aquelas famílias que efetivamente necessitem ser reassentadas". A insatisfação dos habitantes e dos defensores presentes na reunião teria levado à marcação de dois novos encontros, onde os projetos seriam apresentados pela prefeitura. De julho a dezembro, no entanto, os encontros ainda não haviam acontecido. Diante desses fatos, os defensores exigem com a ação diversas informações e comprometimentos. Informam ainda que os agentes não voltaram a aparecer falando sobre remoções, porém "persiste a incerteza sobre o projeto e a necessidade de realocação de moradores anteriormente informada".

Em um termo de declaração que reencontrei junto à petição inicial dos defensores enquanto pesquisava o conteúdo das pastas e, portanto, concomitantemente à leitura do processo eletrônico, havia mais relatos sobre a visita dos agentes do município na área de intervenção. ${ }^{19}$ No curso da pesquisa demorei

18 Utilizo aqui a palavra "defensores", no masculino, porque este processo especificamente foi conduzido por um defensor. Gostaria de ressaltar, no entanto, que a equipe do NUTH, desde sua criação, foi sempre mista, e com um número maior de defensoras atuando frente aos casos.

19 Alguns processos, como o da comunidade do Estradão, só estavam disponíveis por via eletrônica. 
um pouco para compreender que o conteúdo das pastas era muito mais vasto e variado do que os parágrafos contidos no processo. Havia, portanto, uma necessidade de mediação e tradução do material reunido nas pastas à norma jurídica, com suas temporalidades, doutrinas e inclusive limitação de seus operadores e juízes. Não analisarei esse percurso de mediação aqui; no entanto, é importante ressaltar que ele é parte fundamental do trabalho dos defensores públicos, dos servidores públicos e estagiários, e reflete, no caso do NUTH, o compromisso ético e político com aqueles e aquelas que atendem.

Retornando ao termo de primeiro atendimento, na parte chamada de "Informações sobre a ocupação", vemos que uma das declarantes afirma que reside na comunidade desde 1997, sabemos que ela tem certeza e lembra bem deste ano porque a servidora escreve entre parênteses "(ano do seu casamento)". Seu marido, que hoje tem 40 anos, "nasceu e foi criado no local". A segunda declarante afirma que nasceu ali, já que sua avó é funcionária do hospital que existe na região e trabalha lá há 40 anos. Ela faz questão de incluir no termo que reside com sua mãe, avó, seu pai e seus quatro irmãos, "sendo três menores de idade”. Já o terceiro declarante se aposentou em 1993 e mora na mesma residência desde 1962. Logo abaixo, no fluxo do texto corrido, há o que chamo de parágrafo-nota, onde é retomada a cessão do Estradão ao município, sendo então uma das obrigações da municipalidade a regularização fundiária - além da revitalização de outras áreas do Estradão -, tendo recebido para isso verba federal, visto que o PAC teria criado o Comitê Gestor do PAC Estradão. Já "Estão no local fazendo casas, ruas e etc.", escreve a servidora. Na outra frase, esta mesma servidora cita que "a comunidade comparecia às reuniões querendo uma resposta da municipalidade quanto ao projeto das obras que estão sendo realizadas no local", algo que foi reforçado também pelo texto dos defensores que moveram a ação meses depois.

O termo não cita, mas em algum momento esse comitê gestor se torna "pró-moradia" e uma comissão deste programa vem "pedindo reuniões com a comunidade desde janeiro de 2013", informam os declarantes. O texto também não menciona, mas o Pró-Moradia é um programa do Governo Federal operado pela Caixa Econômica Federal e que, conforme explicitado no site, "tem o objetivo de ajudar famílias em situação de risco social a conseguir melhor moradia e mais qualidade de vida". ${ }^{20}$ Conforme as declarantes, nessas reuniões do Pró-Moradia são tratados assuntos diferentes daqueles que as

20 Conforme disponibilizado no site, o recurso para as moradias vem do Fundo de Garantia do Tempo de Serviço (FGTS), com contrapartida do solicitante - estados, municípios, distrito federal e empresas públicas. Ele é destinado a famílias com renda mensal de até R\$ 1.395,00 e "conta com a experiência técnica da Caixa para auxiliar na análise e no acompanhamento dos projetos", diz o site. Ver < http://www.caixa.gov.br/poder-publico/programas-uniao/habitacao/pro-moradia/Paginas/default. aspx $>$ (última consulta em outubro de 2017). 
moradoras gostariam, já que reclamam na Defensoria para obtenção de informações sobre o teor das obras no entorno de suas casas. Segundo o texto do termo, os moradores vêm pedindo a realização das reuniões para obter informações sobre as moradias e a qualidade das intervenções; no entanto, nos encontros "é falado sobre 'dengue', 'saúde bucal' e para a última reunião prometeram o comparecimento da $\mathrm{Sr}^{\text {a }}$ Bianca [engenheira], mas quem apareceu foi a Sr. ${ }^{a}$ Sonia". Quando apareceu, a "Sr. ${ }^{a}$ Sonia" teria dado três opções à comunidade: "compra assistida, indenização ou casas que estão sendo feitas na [nome de uma localidade dentro do Estradão] e ainda explicou que não era vantagem optar pela compra assistida ou indenização porque o valor é muito baixo, o ideal seria a casa". Conforme ressaltamos no início do texto, as alternativas dadas pelos agentes - dos quais, normalmente, se conhece apenas o primeiro nome - são na maior parte das vezes retóricas, já que são desencorajadas em face da opção que é mais conveniente para o município. Ocorre, no entanto, neste caso, e seguindo o texto do termo, "que a casa é muito pequena - $25 \mathrm{~m}^{2}$ distribuídos em 02 andares/12,5 m² para cada andar". As declarantes ressaltam que na comunidade "há idosos, pessoas portadoras de necessidades especiais", citando como exemplo a neta do declarante que tem síndrome de Down. Há um senhor que é vizinho, do qual elas citam o nome, cuja mãe é a moradora mais antiga da comunidade: "ela é idosa e não pode subir escada, ficou sem opção, tendo a Sonia indicado a compra assistida, que ela mesma condenou e disse aos moradores que não fizessem essa opção", apontaram. Dizem que a "Sr. a Sonia informou que a engenheira Bianca já iria começar as medições nas casas dos declarantes na segunda-feira, para calcular indenizações e a metragem do local, mas ela não apareceu". As declarantes dizem que a comunidade já pediu o projeto, mas o "município se omite". Uma das declarantes disse que já solicitou a Sonia "o projeto que será desenvolvido no local e para onde serão manejados", porém teria sido informada que "isto depende da prefeitura liberar a engenheira". As declarantes alegam para a servidora que não é correto retirarem os moradores que estão lá há cerca de 40 anos "para colocarem pessoas de fora", que o projeto deve fazer a inclusão das famílias que já vivem lá e tonar possível acomodar todos e todas com "um mínimo de dignidade". Seguem dizendo que a Sr. ${ }^{a}$ Sonia disse que o projeto para o local está pronto desde 2009, mas eles alegam que nunca houve informação clara sobre ele. Uma das declarantes diz que o irmão tem um problema nos ossos que impede que desça e suba escadas; além disso, questiona como irão viver os oito em uma casa de $25 \mathrm{~m}^{2}$. Elas declaram também que a prefeitura, "no contexto dessas obras”, "abriu um 'valão' dentro da comunidade que está cheio d'água e virou foco de mosquitos, ratos, baratas que agora passam a 'conviver' com os moradores”. Declaram que há um espaço dentro da comunidade onde alguns caminhões da prefeitura retiram pela noite a terra 'preta' para ser vendida e no local despejam entulho de obra, o que "também virou foco de vetores". 


\section{DESDOBRAMENTOS FUTUROS}

Tal como busquei descrever, os termos de declaração me pareceram um material relevante, tanto como narrativa das dimensões do conflito na gestão da habitação social e da dinâmica que envolve as intervenções urbanas em áreas periféricas, quanto como possibilidade de reencenar a relação de escuta e escrita entre o servidor ou estagiário e o declarante, nos mostrando, portanto, a tessitura dessa possibilidade de resistência - pela via estatal - e o esforço em tornar legíveis as tramas que envolvem a construção da opacidade das esferas governamentais nestas localidades. Todo o conteúdo das pastas e a filtragem para produção dos processos me pareceram importantes para refletir sobre práticas de Estado e de resistência e sobre como elas englobam de maneira distinta a produção de diversos documentos. Seguindo Ferreira, a metodologia que orienta a pesquisa aqui descrita não está em busca de dados de um "suposto mundo real cuja verdade se queira descrever" (2015: 13). Tal como destaca Ferreira, como parte de sua metodologia de pesquisa, na qual também estamos orientadas, o acesso aos registros documentais é atrelado a um interesse específico da pesquisa e a uma censura determinada pelas normas da escrita acadêmica atenta a segurança dos interlocutores (2015: 29). Das (2004: 235) também destaca que não será precisa em fornecer datas ou locais específicos; e, de acordo com a autora, também modificamos os nomes utilizados nos casos a fim de garantir o anonimato e a integridade dos envolvidos no processo. ${ }^{21}$

Na reescrita dos termos, e na descrição de partes do processo, busquei me transportar para a pequena sala onde geralmente são realizados os primeiros atendimentos. A escuta do servidor, como já mencionado, é qualificada e está presente na materialidade do termo. Sua experiência no atendimento de diversos casos similares ao do Estradão naquele período aparece em uma parte que nominei de parágrafo-nota, que é quando esse funcionário acrescenta ao termo informações que já possui sobre o processo e seu histórico, com a intenção de contextualizar posteriormente para o defensor os dados que podem ser relevantes para "os fatos" do processo.

Como os processos são, na maioria das vezes, longos, muitos dos moradores foram assistidos por diferentes defensores e defensoras, distintos grupos de estagiárias e estagiários no interior da Defensoria. É preciso destacar que atualmente - o que nem sempre acontece em relação a outros estados - o Núcleo de Terras e Habitação tem a confiança daqueles que o procuram. Durante os anos aos quais se dedicou a pesquisa, houve ciclos mais obscuros - 2011 e 2013 - em que os objetivos e a orientação desse núcleo ficaram na sombra

21 Adotando essa orientação da confidencialidade na construção dos casos estudados por esta pesquisa nos processos judiciais do NUTH, isso também foi seguido no que se refere ao corpo de funcionários e estagiários. 
do governo municipal, o que acarretou em mais atrasos, silêncios e "interpretações" diversas das ações dos agentes do município nas favelas. ${ }^{22}$ Uma das etapas que integram a produção do processo de assistência jurídica é composta por reuniões com os moradores, onde eles são atendidos pelos defensores e defensoras e relatam o ocorrido nas entranhas de seu cotidiano, sua vivência entre jogos e estratégias de diferentes poderes. Durante esses dois ciclos, em que o Núcleo teve sua autonomia controlada através de um arranjo político que interferiu na composição do quadro de defensores, os moradores ficaram desconfiados de participar desses atendimentos, com receio de que o que fosse ali relatado chegasse até aqueles que promoviam ou participavam desses jogos de poder, muitos deles integrantes da prefeitura, ou mesmo moradores da favela que trabalhavam nela. $\mathrm{Na}$ falta de espaços de diálogo no interior da institucionalidade, não faltaram reivindicações dos moradores e militantes da causa da moradia pela retomada da autonomia e "integridade" da Defensoria Pública, o que acabou acontecendo em 2015. O momento em que realizei a pesquisa é, portanto, um momento entre ciclos, onde os moradores e militantes observam com positividade a pessoalidade com que os defensores atuam na administração burocrática, fazendo questão de visitar os locais de moradia dos atendidos e prestando muitas vezes a assistência nos próprios territórios de conflito. ${ }^{23}$

Conforme buscamos descrever ao longo do artigo, torna-se evidente que a participação em um processo envolve o sujeito em uma "aura de operação legal" (Das 2007: 241), onde os papéis recebidos são guardados em pastas com todo o cuidado, levados para a Defensoria como documentos com potencial de serem convertidos em prova judicial, são documentos que têm vida e têm história. Por essa importância na vida dos "assistidos" e pelo potencial do processo enquanto registro sincrônico e diacrônico da relação desses grupos com o Estado e seus ilegalismos, apostamos nesta pesquisa enquanto contribuição para o conhecimento já elaborado na área da antropologia do Estado.

Em meu doutorado refleti sobre o efeito da inteligibilidade (Das 2004) do Estado na vida dos interlocutores integrantes de redes de contestação aos megaeventos - no Rio de Janeiro, e também em Porto Alegre, onde fiz parte de meu trabalho de campo. Usei a categoria de resiliência para explicitar uma temporalidade da resistência, que primava por uma performance não pública dos interlocutores em busca de energia, razões, afetos, fé que pudessem nutri-los para "seguir em frente", seguir com dignidade, porém em busca de que ela fosse reconhecida pela racionalidade de Estado, pelas instituições e seus

22 Aqui destaco o trabalho de Alexandre Mendes (2014), ex-defensor do NUTH, que tem escrito sobre os diferentes ciclos do Núcleo.

23 Letícia Ferreira (2015) destaca que não é porque são documentos e porque os funcionários são parte da administração altamente burocrática que esses processos são isentos de pessoalidade, seja na forma de apego, seja no cuidado, seja por interesse. 
funcionários. Os processos na Defensoria Pública eram parte desse arcabouço de estratégias de sobrevivência.

Antes de finalizar, é importante destacar que, tal como refletimos em outros trabalhos (Gutterres 2016), entendemos a remoção de moradias - tal qual ela é produzida pelo município - como uma das faces da (des)habitação dos pobres nas regiões em que vivem, e esta última como um ato mais profundo de desarticulação e desconstrução de redes de afeto e de convivência que são estabelecidas a partir da partilha de espaços coletivos comuns, caminhos e percursos. Ressalto ainda que o que apresentamos aqui é um exercício sobre como interpretar esses dados, documentos, campos, personagens e situações burocráticas diversas. Torna-se um segundo desafio fazer esse exercício com aproximadamente outros 150 processos - com suas pastas, suas particularidades processuais e momentos políticos distintos.

\section{BIBLIOGRAFIA}

DAMO, Arlei Sander, e Ruben George OLIVEN, 2013, "O Brasil no horizonte dos megaeventos esportivos de 2014 e 2016: sua cara, seus sócios e seus negócios”, Horizontes Antropológicos, 19 (40): 19-63.

DAS, Veena, 2004, "The signature of the State”, em V. Das e D. Poole (orgs.), Anthropology in the Margins of the State. Santa Fe, School of American Research Press, 225-252.

DAS, Veena, 2007, Life and Words: Violence and the Descent into the Ordinary. Berkeley e Los Angeles, CA, University of California Press.

faulHaber, Lucas, 2012, Rio Maravilha: Práticas, Projetos Políticos e Intervenção no Território no Início do Século XX. Rio de Janeiro, Instituto de Pesquisa e Planejamento Urbano e Regional, Universidade Federal do Rio de Janeiro, dissertação de mestrado.

FERNANDES, Adriana, 2013, Escuta Ocupação: Arte do Contornamento, Viração e Precariedade no Rio de Janeiro. Rio de Janeiro, Programa de Pós-Graduação em Ciências Sociais, Universidade do Estado do Rio de Janeiro, tese de doutorado.

FERREIRA, Letícia Carvalho de Mesquita, 2013, "Pesquisar e participar da formulação de uma causa pública: notas etnográficas sobre o desaparecimento de pessoas no Brasil", Revista Campos, 14 (1-2): 195-216.

FERREIRA, Letícia Carvalho de Mesquita, 2015, Pessoas Desaparecidas: Uma Etnografia para Muitas Ausências. Rio de Janeiro, Editora da UFRJ.

FONSECA, Claudia, 1997, "Ser mulher, mãe e pobre", em Mary del Priore (org.), História das Mulheres no Brasil. São Paulo, Editora Contexto, 510-553.

FONSECA, Claudia, 2004, "A certeza que pariu a dúvida: paternidade e DNA", Estudos Feministas, 12 (2): 13-34.

FOUCAULT, Michel, 2008, O Nascimento da Biopolítica. São Paulo, Martins Fontes. 
GUTTERreS, Anelise dos Santos, 2014, A Resiliência enquanto Experiência de Dignidade: Antropologia das Práticas Políticas em Um Cotidiano de Lutas e Contestações Junto a Moradoras Ameaçadas de Remoção nas Cidades Sede da Copa do Mundo 2014 (Porto Alegre, RS e Rio de Janeiro, RJ). Porto Alegre, Programa de Pós-Graduação em Antropologia Social, Instituto de Filosofia e Ciências Humanas, Universidade Federal do Rio Grande do Sul, tese de doutorado.

GUTTERRES, Anelise dos Santos, 2016, "O rumor e o terror na construção de territórios de vulnerabilidade na zona portuária do Rio de Janeiro”, Mana 22 (1): 179-209.

LIMA, Antonio Carlos de Souza, 1995, Um Grande Cerco de Paz: Poder Tutelar, Indianidade e Formação do Estado no Brasil. Petrópolis, Vozes.

LUGONES, Maria Gabriela, 2009, Obrando en Autos, Obrando en Vidas: Formas e Fórmulas de "Proteção Judicial" dos Tribunais Prisionais de Menores de Córdoba, Argentina, no Começo do Século XXI. Rio de Janeiro, PPGAS, Museu Nacional, Universidade Federal do Rio de Janeiro, tese de doutorado.

MAGALHÃES, Alexandre, 2013, Transformações no "Problema Favela" e a Reatualização da "Remoção" no Rio de Janeiro. Rio de Janeiro, Instituto de Estudos Sociais e Políticos, Universidade do Estado do Rio de Janeiro, tese de doutorado.

MENDES, Alexandre, 2014, "A nova luta da Vila Autódromo e dos moradores que resistem à remoção: reconstruir a Defensoria Pública e sua autonomia”, Lugar Comum, 42: 77-84.

OliveirA, Rachel Barros de, 2016, Urbanização e "Pacificação" em Manguinhos: Um Olhar Etnográfico sobre Sociabilidade e Ações de Governo. Rio de Janeiro, Instituto de Estudos Sociais e Políticos, Universidade do Estado do Rio de Janeiro, tese de doutorado.

PEIRANO, Mariza, 1986, “'Sem lenço, sem documento': reflexões sobre cidadania no Brasil", Sociedade e Estado, 1 (1): 49-64.

RILES, Annelise, 2006, "Introduction: in response", em Annelise Riles (org.), Documents: Artifacts of Modern Knowledge. Ann Arbor, The University of Michigan Press, 1-38.

SCHUCH, Patrice, 2009, Práticas de Justiça: Antropologia dos Modos de Governo da Infância e Juventude no Contexto pós-ECA. Porto Alegre, Editora da UFRGS.

SILVA, Marcella Carvalho de Araújo, 2016, "Entre as estatísticas e a cidade: o cadastramento e a produção da demanda social por apartamentos no Programa Minha Casa Minha Vida”, Cadernos Metrópole, 18 (35): 237-256.

SILVA, Luiz Antonio Machado da, e Ademir FIGUEIREDO, 2015, "Urbanização x remoção", em L.A. M. SILVA, Fazendo a Cidade: Trabalho, Moradia e Vida Local entre as Camadas Populares Urbanas. Rio de Janeiro, Mórula Editor, 70-83.

VIANNA, Adriana de Resende B., 1999, O Mal que Se Adivinha: Polícia e Menoridade no Rio de Janeiro (1910-1920). Rio de Janeiro, Arquivo Nacional. 